\title{
The Effect of a Single Shrub on Wind Speed and Nabkhas Dune Development: A Case Study in Kuwait
}

\author{
Jasem M. Al-Awadhi \\ Department of Earth and Environmental Sciences, Faculty of Science, Kuwait University, Kuwait City, Kuwait \\ Email: jawadhi@kuc01.kuniv.edu.kw
}

Received October 26, 2013; revised November 28, 2013; accepted December 25, 2013

Copyright (C) 2014 Jasem M. Al-Awadhi. This is an open access article distributed under the Creative Commons Attribution License, which permits unrestricted use, distribution, and reproduction in any medium, provided the original work is properly cited. In accordance of the Creative Commons Attribution License all Copyrights (C) 2014 are reserved for SCIRP and the owner of the intellectual property Jasem M. Al-Awadhi. All Copyright (C 2014 are guarded by law and by SCIRP as a guardian.

\begin{abstract}
Thirty coastal nabkhas were selected for morphometrical measurements. The studied nabkhas were mostly elongated, with an average total length of about $12.9 \mathrm{~m}$, an average width of $3.4 \mathrm{~m}$, and an average height of 1.2 m. Optical porosity of nabkha shrub crown was measured and no apparent relationship with the horizontal size of trapped wind laden sand was found. A simple wind tunnel experiment was carried out to investigate the horizontal wind-flow distribution across a pro-typed shrub. The results of the experiment revealed that the degree of wind sheltering might extend up to a downwind distance approximately equal to 4.5 times the height of the shrub, where an effective velocity recovery started.
\end{abstract}

\section{KEYWORDS}

Nabkhas; Sediment; Porosity; Wind Tunnel

\section{Introduction}

Nabkha is a type of Aeolian landforms, which is commonly developed as a result of sand accumulation around coastal and desert shrubs [1]. The morphology of nabkhas is controlled by growth patterns of shrub [2]. The height of nabkha, to some extent, is related to the height of the shrub crown, while its length is related to the overall height of the shrub [3], width of the basal shrub and wind velocity [4]. Other important factors controlling nabkhas morphology include type of sediment supply and climate [5] as well as the porosity of the shrub crown (e.g., [2]). The wind regime is a major climatic factor that influences Aeolian processes including nabkha development [7]. The air-flow patterns over nabkhas were studied in a series of wind-tunnel experiments by Zhizhong et al. [8]. Nabkhas form a surface roughness, where they interact with airflow and, therefore, cause significant variations in wind velocity and direction over the surface.

Grant and Nickling [9] carried out a field study to investigate the effect of vegetation porosity (leaf density) on the drag coefficient of small conifer trees $(1.4 \mathrm{~m}$ in height). They found that the porous element had a higher drag coefficient than a solid element, and the drag coefficient changed on a continuum with porosity, reaching a peak at an intermediate porosity value (0.32), and eventually falling to zero when the element was removed. Grant and Nickling [9] came to a conclusion that this peak in the drag coefficient (momentum extraction of vegetation) versus porosity curve corresponded to shelterbelt efficiency that peaked at medium-porosities.

Aeolian processes including deflation, transportation and deposition are very active in Kuwait, where they are related to the dry, hot, windy climate, the detrital nature of bed rock and its location downwind from the highdeflation area of Mesopotamian floodplain [10,11]. As a result, more than $50 \%$ of the Kuwait surface is covered by 13 mobile sandy bodies. These are continually drifted along the surface by wind, mainly during the summer season (May to September), to form different land forms including coastal nabkhas [12]. To provide a better understanding of the mechanism of nabkha development, this paper discusses the results of the horizontal windflow distribution across a pro-typed shrub, obtained from a wind-tunnel experiment and supported by field measurements of horizontal size of trapped wind laden sand 
around shrubs.

\section{Materials and Methods}

An attempt was made to carry out field measurements of morphometrical characteristics of thirty coastal nabkhas to support the results of the wind-tunnel. The morphmetric parameters are defined in Figure 1. The field study area is located within the northern coastal plain of $\mathrm{Ku}$ wait Bay and downwind of the major mobile sand corridor extending continuously from the northwestern border of Kuwait in a SE direction. The study area is well described by Al-Awadhi and Al-Dousari [13]. In this study, another attempt was also made to investigate the effect of shrub crowns porosity $(p)$ of nabkhas on the horizontal dimension of sand trapped using image processing technique built in PAX-it software. Digital images of the shrubs, with placing a red board behind the shrub as a distinguish background, were captured and analyzed for determining the porosity percentage. The angle of incidence of the image was selected to be consistent with the dominant wind direction (NW).The porosity of the shrub was then calculated as the percentage of red spots to the total selected area (Figure 2). For each shrub two images were captured, one upwind side and other downwind side, the calculated values were then averaged for the porosity percentage.

Variation in up and downwind velocities over protyped shrub due to its interaction with airflow was determined by conducting a simple experiment using the
Kuwait Institute for Scientific Research (KISR) wind tunnel (20 m long wind tunnel with a test-section dimension of $1.2 \mathrm{~m}$ wide and $0.95 \mathrm{~m}$ height). The wind tunnel is of the blower type driven by a centrifugal fan. The components of the wind tunnel are shown in Figure 3.

A profile for wind flow distribution across a single shrub model $(10 \mathrm{~cm}$ height $)$ was obtained by using Dwyer Pitot-static tubes fixed at a height of $15 \mathrm{~cm}$; i.e., 5 $\mathrm{cm}$ above the height of the model. As a reference point, the mean velocity was also measured at $140 \mathrm{~cm}$ upstream from the upwind edge of the model, on continuous bases at the same height; i.e., $15 \mathrm{~cm}$. For a better simulation with the case in the field: 1 ) the tested shrub model was erected among other similar shrub models in the testsection of the wind tunnel along a line perpendicular to the flow direction and uniformly spaced at a center-tocenter distance of $10 \mathrm{~cm}$ (Figure 4); 2) the whole upstream length of the wind tunnel up to upwind edge of the model was laden by a sand of median grain size equal to $0.25 \mathrm{~mm}$, obtained locally from the slip face of a barchan dune; and 3) based on the field measurements, the shrub model crown $(7.5 \mathrm{~cm})$ was lifted up from the wind tunnel testing floor to a height equal to $50 \%$ of its total height; this height represents the average height of nabkha dune crest, measured in the field, with respect to the its shrub height; and 4) a preselected velocity $(6.3 \mathrm{~m} / \mathrm{s}$; fan-settings $=11 \mathrm{~Hz}$ ) representing an average wind speed during summer period where Aeolian processes are active.

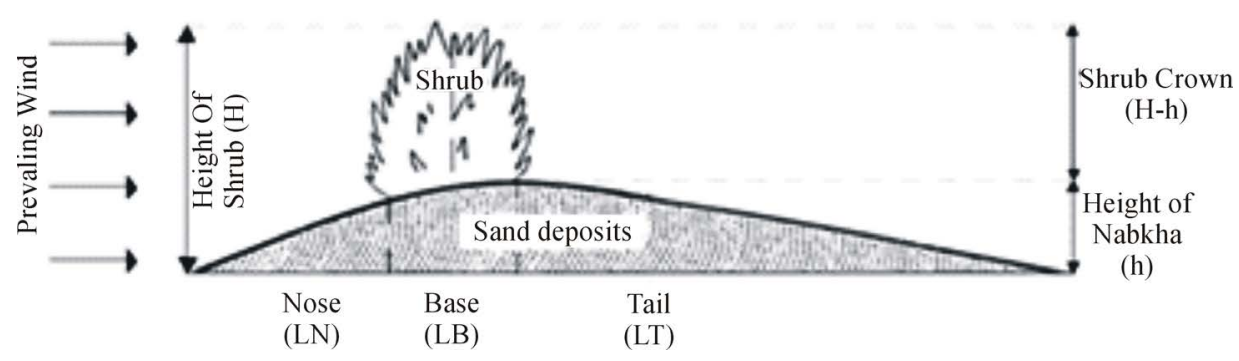

Figure 1. Schematic diagram illustrating the morphometric parameters of nabkhas.

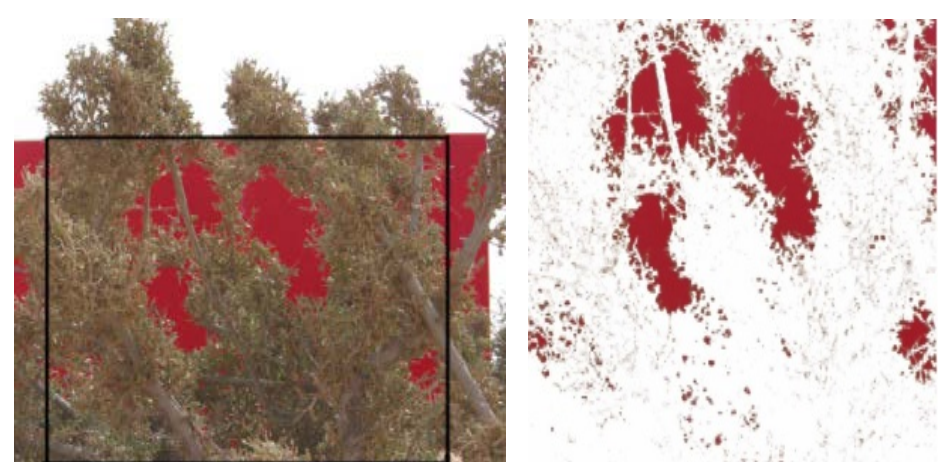

Figure 2. Change detection input and output showing the size and distribution of air void, in shades of dark color, within a nabkha shrub. 


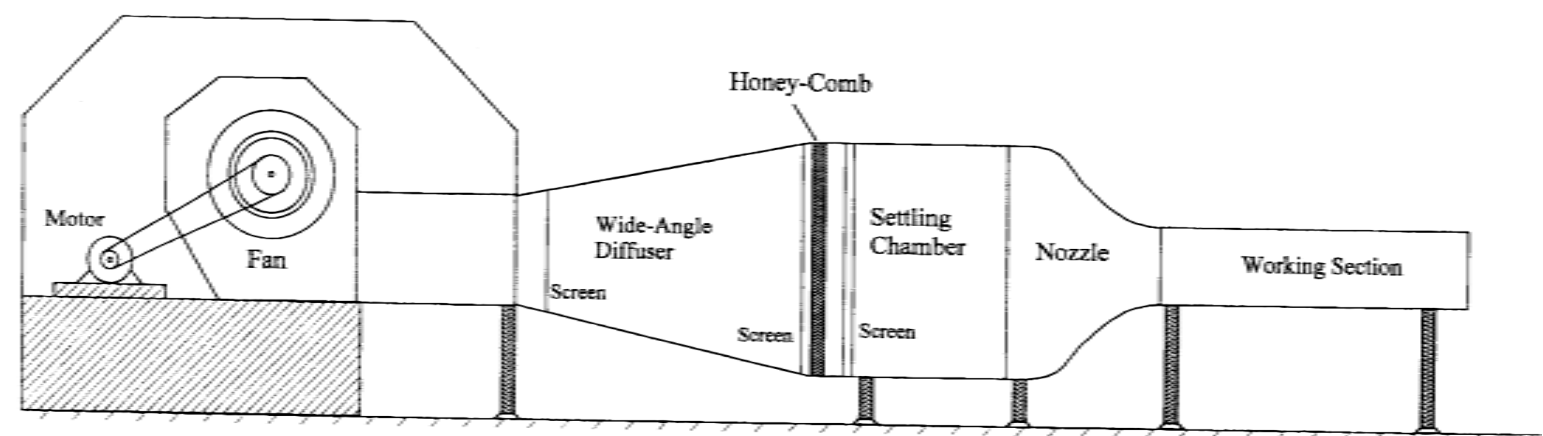

Figure 3. Components of Kuwait Institute for Scientific Research (KISR) wind tunnel.

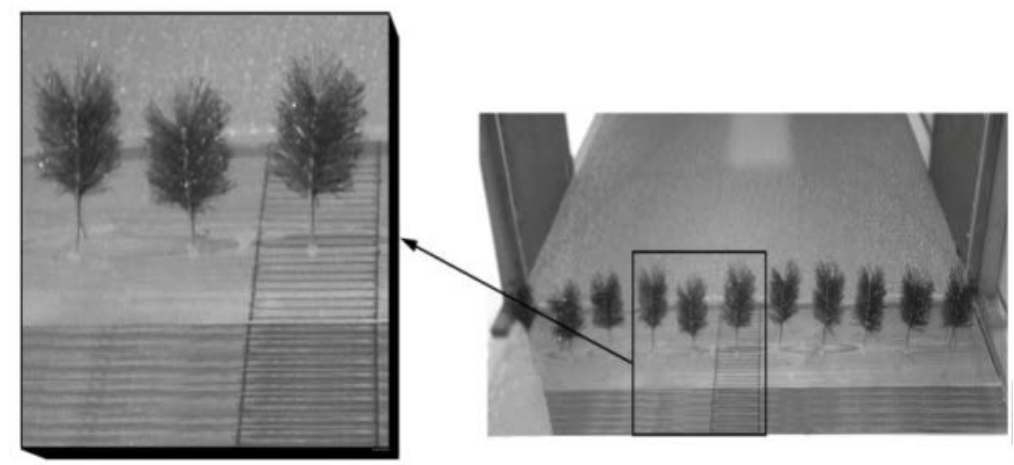

Figure 4. Experimental setup showing the erection of pro-typed shrub models across the test-section of the wind tunnel.

\section{Result}

\subsection{Morphometrical Parameters of the Studied Nabkhas}

The studied nabkhas have an oval shape elongated parallel to the NW prevailing wind direction. Measurements of the morphometrical parameters of the studied nabkha are presented in Table 1 . The total length (L) of nabkha dunes varies between 8 and $18 \mathrm{~m}$ with an average of 12.8 $\mathrm{m}$, while their width (W) across their crest ranges between 2.1 and $4.9 \mathrm{~m}$. The length of the base (LB), where the shrub grows, varies between 1.7 and $4.3 \mathrm{~m}$ with an average of $2.9 \mathrm{~m}$. The length of the tail (LT) varies between 4.1 and $10.8 \mathrm{~m}$ with an average of $7.1 \mathrm{~m}$, while the length of the nose (LN) varies between 1.2 and $4.3 \mathrm{~m}$ with an average of $2.8 \mathrm{~m}$.

The crest height of the nabkhas (h) ranged between 0.5 to $2.6 \mathrm{~m}$ above their base level with an average of $0.9 \mathrm{~m}$, while the height of shrub $(\mathrm{H})$ ranged between 1.1 to 3.7 $\mathrm{m}$ above the ground with an average of $1.8 \mathrm{~m}$. The optical porosity of shrubs crown $(p)$, the percentage of voids to total area of the shrub, of the studied nabkhas ranged between $7.1 \%$ to $18 \%$ with an average of $11.7 \%$. Using the relationship obtained by Grant and Nickling [9]:

$$
o p=v p^{2.782}
$$

where $o p$ is the optical porosity and $v p$ is the volumetric porosity, the volumetric porosity (3-diemtional porosity- the percentage of voids to total volume of the shrub) of the studied nabkhas ranged between $38.6 \%$ to $54 \%$ with an average of $46 \%$.

Figure 5 illustrates the effect of shrub porosity $(p)$ on the length dimensions of sand trapped. The figure weakly reveals that as the porosity increases the horizontal length of the nabkha decreases; i.e., it reveals weak correlations of such effect either on total length (L) or partial length (LN or LT). The possible explanation for such weakness in relationship is that the air flow, carrying the sediments, passing the shrub may vary due to high variation in the porosity over the upwind shrub coverage area (leaf density), thus restricting the maximum growth of the nabkha in the horizontal as well as vertical directions. The other possible explanation could be related to the difficulty with using optical porosity; i.e., two elements of similar optical porosities may have significantly different amounts of pore space within them, altering the way in which the wind would interact with these elements [9]. For this reason, the crown porosity of the tested shrub model, used in the wind tunnel experiment, was not taken into consideration.

\subsection{Wind Flow Pattern across a Shrub}

Nabkha dunes are formed as a result of significant variations in wind velocity caused by the interaction of the shrub with airflow carrying Aeolian sand. Such variations 
Table 1. Morphometrical parameters of the studied nabkhas (all values in $\mathbf{m}$ ).

\begin{tabular}{|c|c|c|c|c|c|c|c|}
\hline No. & $\mathrm{H}$ & LN & LB & $\mathrm{LT}$ & h & W & $P(\%)$ \\
\hline 1 & 2.1 & 3.3 & 2.5 & 6.3 & 1.2 & 4.9 & 11.4 \\
\hline 2 & 1.8 & 2.5 & 2.5 & 4.9 & 0.8 & 2.6 & 7.6 \\
\hline 3 & 1.7 & 1.2 & 2.4 & 4.4 & 0.8 & 2.7 & 13.6 \\
\hline 4 & 1.4 & 2.4 & 2.6 & 7.6 & 0.7 & 2.7 & 9.5 \\
\hline 5 & 1.8 & 2.9 & 3.9 & 4.9 & 1.4 & 3.7 & 13.6 \\
\hline 6 & 1.5 & 2.4 & 2.2 & 8.1 & 0.6 & 2.2 & 11.9 \\
\hline 7 & 2.3 & 3.3 & 2.6 & 7.1 & 0.9 & 4.3 & 11.0 \\
\hline 8 & 2.7 & 2.4 & 1.9 & 5.5 & 1.0 & 3.7 & 10.7 \\
\hline 9 & 1.1 & 3.9 & 2.9 & 7.9 & 1.1 & 3.7 & 7.1 \\
\hline 10 & 1.6 & 3.1 & 3.8 & 9.1 & 1.0 & 3.8 & 10.6 \\
\hline 11 & 1.9 & 2.3 & 1.7 & 5.9 & 0.7 & 2.1 & 8.4 \\
\hline 12 & 1.8 & 2.9 & 2.6 & 7.4 & 0.9 & 2.9 & 17.7 \\
\hline 13 & 1.2 & 3.6 & 3.3 & 10.1 & 0.7 & 3.6 & 17.2 \\
\hline 14 & 1.5 & 3.4 & 3.1 & 7.1 & 0.7 & 3.1 & 8.7 \\
\hline 15 & 1.8 & 4.3 & 2.9 & 10.8 & 0.9 & 3.2 & 9.3 \\
\hline 16 & 2.1 & 2.1 & 2.9 & 7.6 & 0.9 & 4.1 & 13.2 \\
\hline 17 & 1.9 & 2.6 & 2.3 & 10.5 & 1.1 & 3.8 & 11.3 \\
\hline 18 & 3.7 & 2.5 & 2.2 & 9.5 & 2.6 & 3.6 & 14.1 \\
\hline 19 & 2.1 & 4.1 & 3.5 & 8.1 & 0.9 & 3.8 & 12.7 \\
\hline 20 & 1.4 & 3.4 & 3.5 & 7.1 & 1.0 & 3.6 & 15.0 \\
\hline 21 & 2.0 & 3.9 & 4.3 & 8.1 & 0.9 & 4.3 & 7.2 \\
\hline 22 & 2.3 & 2.3 & 3.4 & 7.1 & 1.3 & 3.8 & 10.5 \\
\hline 23 & 1.3 & 1.9 & 3.4 & 5.1 & 0.5 & 2.1 & 11.1 \\
\hline 24 & 1.1 & 1.9 & 2.4 & 4.8 & 0.6 & 2.3 & 18.0 \\
\hline 25 & 1.3 & 2.7 & 3.3 & 5.9 & 0.7 & 3.5 & 13.0 \\
\hline 26 & 2.2 & 2.8 & 3.0 & 7.5 & 1.0 & 3.4 & 9.6 \\
\hline 27 & 2.8 & 3.7 & 3.4 & 6.3 & 1.0 & 4.0 & 12.4 \\
\hline 28 & 2.0 & 2.4 & 3.2 & 7.3 & 1.0 & 2.9 & 8.1 \\
\hline 29 & 1.8 & 2.8 & 3.9 & 7.3 & 0.8 & 3.4 & 10.1 \\
\hline 30 & 1.3 & 2.2 & 2.1 & 4.1 & 1.0 & 3.1 & 15.9 \\
\hline Ave & 1.8 & 2.8 & 2.9 & 7.1 & 0.9 & 3.4 & 11.7 \\
\hline Max & 3.7 & 4.3 & 4.3 & 10.8 & 2.6 & 4.9 & 18.0 \\
\hline Min & 1.1 & 1.2 & 1.7 & 4.1 & 0.5 & 2.1 & 7.1 \\
\hline
\end{tabular}

in wind velocity were determined by conducting a simple wind tunnel experiment, and Figure 6 shows the nondimensional mean flow distribution measured across a single shrub model.

The figure reveals that the mean wind velocity immediately over the shrub; i.e., the direct interaction with airflow, is increased by a factor of $39 \%$, and greater mean velocity reduction (83\%) occurred downstream from the shrub at a distance 3.5 times its height $(\mathrm{H})$, while in upstream the greater reduction (37\%) occurred

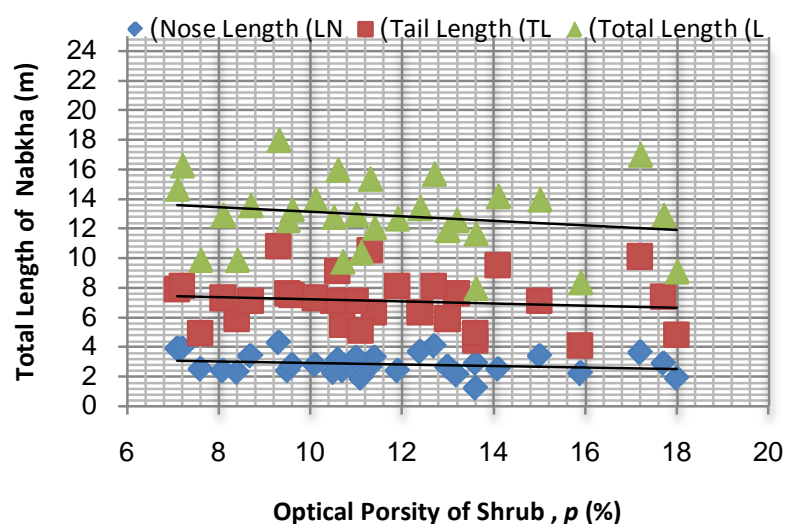

Figure 5. Correlation between lengths of nabkha dune with the shrub porosity $(p)$.

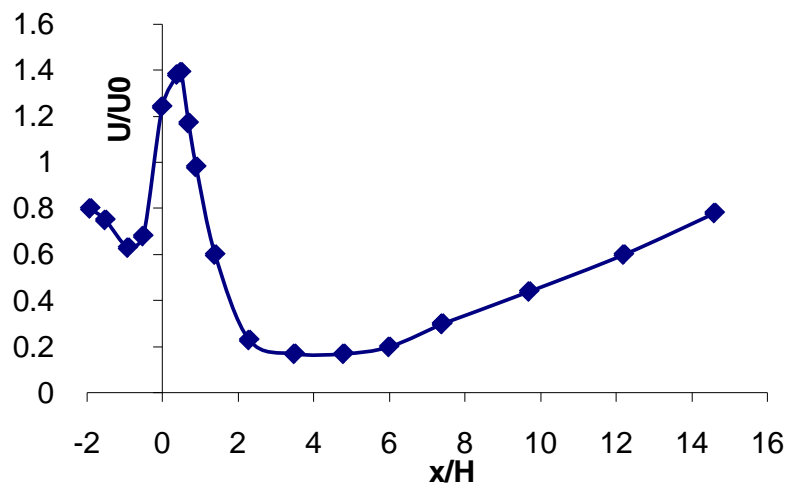

Figure 6. Velocity distribution across a model shrub; $H$ and $x$ are the height of shrub and distance from it, respectively; $\mathrm{U} 0$ is far upstream velocity and $\mathrm{U}$ is velocity at distance $\mathrm{x}$.

at a distance 1 time $\mathrm{H}$. The effective velocity recovery in downstream starts at distance approximately 4.5 times the shrub height, while the effective recovery in upwind stream seems to start at a distance 2 time the shrub height. Greater mean velocity reduction occurred immediately downstream from the shrub with a maximum value at a distance 2 times $\mathrm{H}$.

Relating the wind tunnel findings, shown in Figure 6, with the horizontal dimensions of the studied nabkha dunes, it is obvious that the reduction or the degree of sheltering (tail length of nabkha dune) of studied shrubs extends in average to a downwind distance equal to 3.9 times the height of the shrub, where an effective wind velocity recovery starts $(\mathrm{x} / \mathrm{H}=4)$. Similarly, the upwind deposition forming the nabkha nose extends to an average distance equal to 1.5 times the height of shrub from the base, where an effective upwind velocity reduction starts at $(\mathrm{x} / \mathrm{H}=-2)$. The upwind peak reduction in velocity occurs at $\mathrm{x} / \mathrm{H}=-1$, while the peak reduction in velocity occurs at a downwind distance equal to 2 time the height of shrub $(x / H=2)$, where the crest of nabkha is formed. The length of the base (LB), where the crest occurs and the shrub grows, has an average value equal to 
1.6 times the height of shrub where the peak reduction in velocity occurs. It must be pointed out that these measurements are rather preliminary, but they are encouraging.

The extent of reduction in erosion, or the degree of sheltering sand can be observed from Figure 6. It extends up to an average downwind distance equal to 4.5 times the height of the shrub model $(\mathrm{x} / \mathrm{H}=4.5)$, where an effective velocity recovery starts. This finding agrees with the field measurements stated in the Section 3.1 (morphometric of nabkha); the tail length, which is associated with the degree of sheltering effect, may extend in average 4.7 times $(0.5 \mathrm{LB}+\mathrm{LT})$ that of shrub height. From the same figure, it can be figured out that the upwind deposition forming the nabkha nose may extend to a distance equal to two times the height of the shrub model. Reviewing the field measurements, it was found that the nose may extend in average 2.3 times $(0.5 \mathrm{LB}+$ LN) that of shrub height.

\section{Discussions}

Nabkha is a special depositional Aeolian landform where accumulation of wind-laden particles is facilitated by vegetation as micro-wind breakers. Therefore, the morphometrical characteristics of nabkha sediments are closely related to vegetation morphology [1,14-16]. The nabkha thus grows along with plant, both vertically and horizontally [13].

Despite the importance of the continuous supply of sand, the size variability of nabkhas in the study area is controlled chiefly by the total shrub height [13]. It is also believed that, like sand fence porosity, the optical porosity of the shrub crown may affect the percentage of the trapped sand. The effect of porosity of sand fences on trapping wind laden sands has been studied by many authors [17-21]. Most of related studies concluded in general that there is a relationship between drag coefficient $\left(\mathrm{C}_{\mathrm{d}}\right)$ (wind force) and the optical porosity (op), and the most effective porosity in reducing the mean, nearground wind speeds for the longest distances (10 to 15 times the height of the porous fence) ranges between $30 \%$ to $50 \%$. Taylor [22] presented a curve showing the relationship between $\mathrm{C}_{\mathrm{d}}$ and op; the porous elements have higher $C_{d}$ than solid elements and it may increase up to $50 \%$. In this study, however, the investigation of the effect of shrub optical porosity on the horizontal size of trapped wind laden sand does not show apparent relationship in this regard (Figure 5). In addition to the explanations given in the result section, for such weak relationship, the effect of shrub porosity on downwind regime may not be comparable to similar effect of porous fences, simply because a three dimensional porous shrub consists of a number of individual solid leaves, which interact with one another in a flow similar to wake inter- ference. Thus, some momentum would be extracted by an upwind leaf, more by the next downstream leaf, until either all of the momentum is extracted or the other side of the shrub is reached [9]. This will certainly affect the $\mathrm{C}_{\mathrm{d}}$ magnitude and subsequently affect in reducing the mean, near-ground wind speeds for the shortest distances (about 4 times the height of the shrub; (Figure 6)).

It is known that the total forces imparted by the wind to composite surfaces will be portioned between the erodible (nabkha dune) and non-erodible (shrub) surface elements [23]. The main influence of non-erodible element on erosion is sheltering effect. It captures some of the disturbing forces of wind and incoming saltations that would otherwise move the erodible surface sediments [24]; i.e., the shrub decreases the wind grain stress on the nabkha dune surface by absorbing a significant fraction of the downwind momentum flux [24-26]. Thus, the reduction in the flow strength near a shrub bed reduces the sand flux, forming the crest part of nabkha, then part of this flux is deposited upwind and further downwind, forming the nose and tail, respectively, until an equilibrium condition exists between the height of the shrub (including leaf density) and sediment deposition. Accordingly, (Figure 7), based on field and wind-tunnel measurements, illustrates schematically the role of a shrub in interfering wind flow and sediment deposition patterns.

\section{Conclusions}

Wind tunnel experiment on a shrub reveals that greater mean velocity reduction (wake zone) occurs immediately down and upstream from the shrub, where most of the sand flux deposits, forming the crest part of nabkha dune. Then part of this flux is deposited further up and downwind, forming the ends of nose and tail of nabkha at upwind and downwind distances of approximately 2.3 and 4.7 times the height of the shrub, respectively, until an equilibrium condition exists between the height of shrub and wind sediment deposition. Field observations indicate that nabkha dune volume is closely related to shrub height rather than its porosity (leaf density), the higher the shrub the larger the nabkha, while no apparent relationship with respect to the horizontal component of the nabkha is found as the crown porosity of the shrub changes.

The study shows that the pattern of horizontal wind flow reduction in front and behind a shrub is generally in agreement with the horizontal sediment deposition pattern around a shrub.

\section{Acknowledgements}

The author would like to express his appreciation and gratitude to Mr. Nabil Basili for helping in field works. This work was supported by Kuwait University Research 


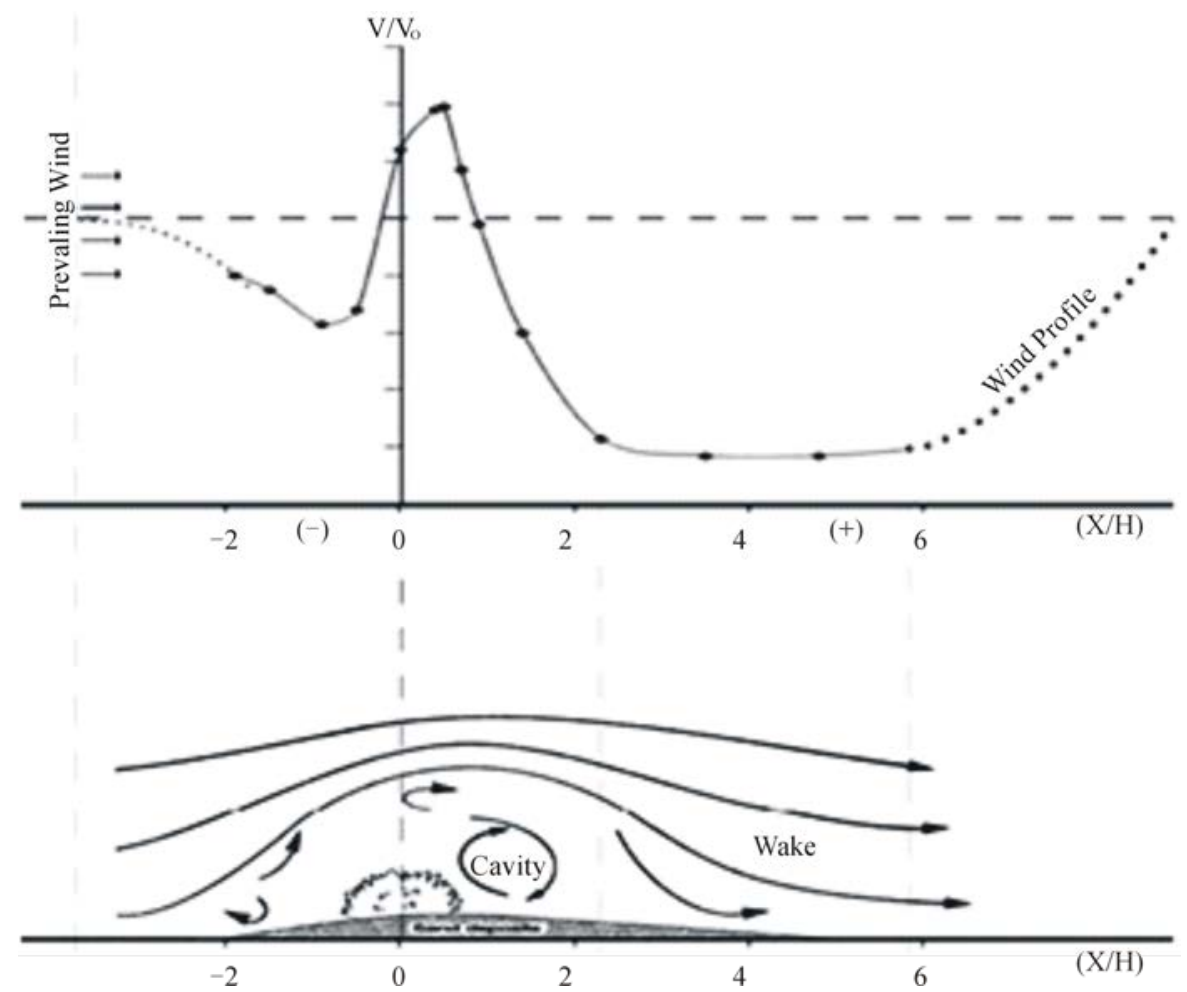

Figure 7. Schematic diagram for wind interference with the shrub to form nabkha dune.

Grant No. [SE01/11].

\section{REFERENCES}

[1] K. Ardon, H. Tsoar and D. G. Blumberg, "Dynamics of Nebkhas Superimposed on a Parabolic Dune and Their Effect on the Dune Dynamics," Journal of Arid Environments, Vol. 73, No. 11, 2009, pp. 1014-1022. http://dx.doi.org/10.1016/j.jaridenv.2009.04.021

[2] A. Tengberg and D. L. Chen, “A Comparative Analysis of Nebkhas in Central Tunisia and Northern Burkina Faso,” Geomorphology, Vol. 22, 1998, pp. 181-192. http://dx.doi.org/10.1016/S0169-555X(97)00068-8

[3] F. I. Khalaf, R. Misak and A. Al-Dousari,” Sedimentological and Morphological Characteristics of Some Nabkha Deposits in the Northern Coastal Plain of Kuwait, Arabia,” Journal of Arid Environments, Vol. 29, No. 3, 1995, pp. 267-292. http://dx.doi.org/10.1016/S0140-1963(05)80107-7

[4] P. A. Hesp, "Ecological Processes and Plant Adaptations on Coastal Dunes,” Journal of Arid Environments, Vol. 21, No. 2, 1991, pp. 165-191.

[5] R. Cooke, A. Warren and A. Goudie, "Desert Geomorphology," UCL Press Limited, University College London, London, 1993.

[6] S. J. Lee, K. C. Park and C. W. Park, "Wind Tunnel Observations about the Shelter Effect of Porous Fences on Sand Particle Movements," Atmospheric Environment, Vol. 36, No. 9, 2002, pp. 1453-1463. http://dx.doi.org/10.1016/S1352-2310(01)00578-7
[7] J. M. Al-Awadhi, A. Al-Hellal and A. Al-Enezi, "Sand Drift Potential in the Desert of Kuwait," Journal of Arid Environments, Vol. 63, No. 2, 2005, pp. 425-438. http://dx.doi.org/10.1016/j.jaridenv.2005.03.011

[8] L. I. Zhizhong, W. U. Shengli, D. L. Janis, G. E. Lin, H. E. Mudan, W. Xiaofeng, J. Jianhui, L. Jinwei, L. I. Wanjuan and M. A. Rong, "Wind Tunnel Experiments of Air Flow Patterns over Nabkhas Modeled after Those From the Hotan River Basin, Xinjiang, China (II): Vegetated," Earth Science China, Vol. 2, No. 3, 2008, pp. 340-345.

[9] P. F. Grant and W. G. Nickling, "Direct Field Measurement of Wind Drag on Egetation for Application to Windbreak Design and Modelling," Land Degradation and Development, Vol. 9, No. 1, 1998, pp. 57-66. http://dx.doi.org/10.1002/(SICI)1099-145X(199801/02)9: $1<57::$ AID-LDR288>3.0.CO;2-7

[10] F. I. Khalaf and D. Al-Ajmi, "Aeolian Processes and Sand Encroachment Problems in Kuwait," Geomorphology, Vol. 5, No. 2, 1993, pp. 111-134. http://dx.doi.org/10.1016/0169-555X(93)90042-Z

[11] A. Al-Enezi, K. Pye, R. Misak and S. Al-Hajraf, "Morphologic Characteristics and Development of Falling Dunes, Northeast Kuwait,” Journal of Arid Environments, Vol. 72, No. 4, 2008, pp. 423-439. http://dx.doi.org/10.1016/j.jaridenv.2007.06.017

[12] J. M. Al-Awadhi and R. M. Misak, "Field Assessment of Aeolian Sand Processes and Sand Control Measures in Kuwait," Kuwait Journal for Science and Engineering, Vol. 27, No. 1, 2000, pp. 156-176.

[13] J. M. Al-Awadhi and A. M. Al-Dousari, "Morphological Characteristics and Development of Coastal Nabkhas, 
North-East Kuwait," International Journal of Earth Sciences (Geologische Rundschau), Vol. 102, No. 3, 2013, pp. 949-958.

http://dx.doi.org/10.1007/s00531-012-0833-9

[14] X. Wang, T. Wang, Z. Dong, X. Liu and G. Qian, "Nebkha Development and Its Significance to Wind Erosion and Land Degradation in Semi-Arid Northern China," Journal of Arid Environment, Vol. 65, No. 1, 2006, pp. 129-141. http://dx.doi.org/10.1016/j.jaridenv.2005.06.030

[15] P. Hesp and A. McLachlan, "Morphology Dynamics, Ecology and Fauna of Arctotheca Populifolia and Gazania Rigens Nabkha Dunes," Journal of Arid Environments, Vol. 44, No. 2, 2000, pp. 155-172. http://dx.doi.org/10.1006/jare.1999.0590

[16] A. J. Dougill and A. D. Thomas, "Nebkha Dunes in the Molopo Basin, South Africa and Botswana: Formation Controls and Their Validity as Indicators of Soil Degradation," Journal of Arid Environments, Vol. 50, No. 3, 2002, pp. 413-428. http://dx.doi.org/10.1006/jare.2001.0909

[17] K. K. Bofah and K. G. Al-hinai, "Field Tests of Porous Fences in The Regime of Sand-Laden Wind,” Journal of Wind Engineering and Industrial Aerodynamics, Vol. 23, 1986, pp. 309-319. http://dx.doi.org/10.1016/0167-6105(86)90051-6

[18] J. E. Cermak, "Advances in Physical Modeling for Wind Engineering,” Journal of Engineering Mechanics, ASCE, Vol. 113, No. 5, 1987, pp. 737-756. http://dx.doi.org/10.1061/(ASCE)0733-9399(1987)113:5( 737)

[19] M. D. Perera, "Shelter Behind Two-Dimensional Solid and Porous Fences,” Journal of Wind Engineering and Industrial Aerodynamic, Vol. 8, No. 1-2, 1981, pp. 93-
104. http://dx.doi.org/10.1016/0167-6105(81)90010-6

[20] G. M. Heisler and D. R. DeWalle, "International Symposium on Windbreak Technology," Reprinted from Agriculture, Ecosystems and Environment, Vol. 22-23, pp. 41-69, Elsevier Science Publishers BV, Amsterdam, 1988.

[21] S. J. Lee, K. C. Park and C. W. Park, "Wind Tunnel Observations about the Shelter Effect of Porous Fences on Sand Particle Movements," Atmospheric Environment, Vol. 36, No. 9, 2002, pp. 1453-1463. http://dx.doi.org/10.1016/S1352-2310(01)00578-7

[22] P. A. Taylor, "Turbulent Wakes in the Boundary Layer," In: W. L. Steffen and O. T. Denmead, Eds, Flow and Transport in the Natural Environment: Advances and Applications, Springer-Verlag, Berlin, 1988, pp. 270-292. http://dx.doi.org/10.1007/978-3-642-73845-6 17

[23] J. M. Al-Awadhi (Abdullah), "Sand Transport and Deposition over Nonerodible Elements,” Ph.D. Thesis, University of Aberdeen, Aberdeen, 1996.

[24] D. A. Gillette and P. H. Stockton, "The Effect of NonErodible Particles on Wind Erosion of Erodible Surfaces," Journal of Geophysical Research, Vol. 94, No. D10, 1989, pp. 12885-12893. http://dx.doi.org/10.1029/JD094iD10p12885

[25] L. K. Marshall, "Drag Measurements in Roughness Arrays of Varying Density and Distribution,” Agricultural Meteorology, Vol. 8, 1971, pp. 269-292. http://dx.doi.org/10.1016/0002-1571(71)90116-6

[26] L. Lyles, R. L. Schrandt and N. F. Schneidler, "How Aerodynamic Roughness Elements Control Sand Movement," Transactions, American Society Agricultural Engineers, Vol. 17, No. 1, 1974, pp. 134-139. http://dx.doi.org/10.13031/2013.36805 